\section{Acute facial nerve palsy in association with acoustic neuroma}

\section{Sir,}

We report a case of acute facial nerve palsy secondary to a haemorrhage into an acoustic neuroma. The function of the nerve had been confirmed to be normal earlier that day by a consultant neurologist. Subsequently there was complete loss of function associated with acute headache.

A 59 year old right-handed woman was transferred from the local eye hospital with a history of episodes of visual blurring when straining for some weeks and a week of gradually increasing loss of vision in the right eye. On direct questioning she admitted to having had poor hearing in the left ear for about 4 years, with intermittent episodes of unsteadiness, exacerbated by head movement. Formal visual field testing (Goldman) revealed an upper temporal defect in the right eye. There was a right relative afferent pupillary defect, bilateral papilloedema, horizontal nystagmus on lateral and vertical gaze bilaterally. The left corneal reflex was diminished and there was sensorineural deafness in the left ear. A plain skull X-ray showed widening of the left internal auditory meatus. Computed tomographic head scan demonstrated a large enhancing lesion arising from the left cerebello-pontine angle with associated obstructive hydrocephalus. A diagnosis of acoustic neuroma was made and the patient commenced on dexamethasone $16 \mathrm{mg} /$ day.

The patient then complained of a sudden pain in the left side of the face that was constant, severe and radiating into the left side of the neck. Approximately 10 minutes after the onset of the pain a left lower motor neurone facial weakness developed that became dense. The patient remained medically unchanged in other respects and the headache slowly resolved. The next day a craniotomy was performed and a large yellowish tumour located. On opening the capsule a considerable haematoma cavity was found containing blood. The seventh and eight nerves were identified, the eighth disappeared into the capsule of the tumour. The seventh followed for some distance but on approaching the internal auditory meatus proved impossible to identify. A complete removal of the visible tumour was obtained. Histology revealed a schwannoma composed predominantly of Antoni B areas.

An acoustic schwannoma (acoustic neuroma) usually arises from the superior component of the vestibular nerve just within the internal auditory meatus, which it invariably expands. The tumour fills the cerebello- pontine angle and eventually may produce severe distortion and displacement of the adjustment brain with hydrocephalus. As would be expected, the eighth nerve is usually affected first but the tumour often compromises other cranial nerves as it expands. The fifth nerve is particularly vulnerable leading to early loss of the corneal reflex, with later numbness and paraesthesia of the face on the appropriate side. ${ }^{1}$ In about $5 \%$ of cases facial numbness may be the first symptom. ${ }^{2}$ Surprisingly, although the facial nerve may be thinly stretched by the tumour, facial nerve weakness is not a prominent sign in many cases pre-operatively. ${ }^{3}$ When facial nerve function is compromised it usually has an insidious onset over several months and is not a sudden event. The operative success of facial nerve preservation correlates with tumour size. ${ }^{4}$ Most series report anatomical preservation to be near $100 \%$ following excision of small tumours, but only $45-55 \%$ in patients having resections of large tumours. ${ }^{5}$ Unfortunately, anatomical continuity does not always result in good long-term facial nerve recovery. ${ }^{3}$ We can find no previous report of an acoustic neuroma having been confirmed as causing an acute facial nerve palsy.

\section{References}

1. Symon, L., Bordi, L.T., Compton, J.S., Sabin, I.H. \& Sayin, E. Acoustic neuroma: a review of 392 cases. Br J Neurosurg 1989, 3: $343-348$.

2. King, T.T., Gibson, W.P.R. \& Morrison, A.W. Tumours of the eighth cranial nerve. Br J Hosp Med 1976, 16: 259-272.

3. Hardy, D.G., Macfarlane, R., Baguley, D.M. \& Moffat, D.A. Facial nerve recovery following acoustic neuroma surgery. $\mathrm{Br}$ J Neurosurg 1989, 3: 675-680.

4. DiTullo, M.V., Malkasian, D. \& Rand, R.W. A critical comparison of neurosurgical and otolaryngeal approaches to acoustic neuromas. J Neurosurg 1978, 48: 1- 12.

5. Gardener, G. \& Robertson, J.H. Hearing preservation in unilateral acoustic neuroma surgery. Ann Otol Rhinol Laryngol 1988, 97: 55-66. 